\title{
Obesity and the Frailty Syndrome at Period of Covid-19
}

\author{
Carmine Finelli*1,2 \\ ${ }^{1}$ Department of Internal Medicine, Pollena (Napoli), Italy \\ ${ }^{2}$ Covid Hospital Boscotrecase, Boscotrecase (Napoli), Italy \\ *Corresponding author: Carmine Finelli, Department of Internal Medicine, Ospedale Cav. R. Apicella - ASL Napoli 3 Sud, \\ Via di Massa, 1, 80040 Pollena (Napoli), Italy
}

\begin{tabular}{|c|c|}
\hline ARTICLE INFO & ABSTRACT \\
\hline Received: 㗀 February 06, 2021 & $\begin{array}{l}\text { Citation: Carmine Finelli. Obesity and the Frailty Syndrome at Period of Covid-19. Biomed } \\
\text { J Sci \& Tech Res 33(5)-2021. BJSTR. MS.ID.005470. }\end{array}$ \\
\hline
\end{tabular}

Published: 㓞 February 15, 2021

\section{Editorial}

The geriatric syndrome of frailty is a physical weakness condition defined by complex multifactorial instability and loss of physiological reserve [1-4]. It is related to clinical manifestations and an elevated risk of injury, higher use of health care and mortality [5,6]. An objective interpretation of the phenotype of frailty, including weight loss, slowness, fatigue, poor tolerance for exercise and weakness, has indeed been suggested. Three of these frailty markers were known to characterize the complete frailty syndrome, while the existence of one or two frailty syndromes was known to be linked to an increased risk of frailty. By using concept, the frequency of various illnesses, like heart failure, atherosclerotic diseases and diabetes mellitus, has been shown to be higher in older adults with frailty.

While obesity is well documented to be correlated with disability [7], its relationship with frailty syndrome was much less evident, especially when frailty is regarded a debilitating disorder $[8,9]$ and weight loss is a probable but not required element of frailty syndrome. In particular, there's really discussion about misunderstanding, since being overweight can greatly contribute to slowness and poor tolerance for exercise. There are, furthermore, many reasons to postulate a link between obesity and frailty based on physiology. First, in obese patients with a disparity between fat and muscle, many studies have discovered a specific syndrome of "sarcopenic obesity" [10-13]. This syndrome is termed to be directly associated with reduced especially with the rising mobility disability [10]. Second, biomarkers correlated with frailty are higher in overweight people, especially inflammatory markers such as C-reactive protein (CRP) and interleukin-6 [3,14]. Current news has shown that even there are low carotenoids in overweight/obese patients [15]. A "obese frailty" syndrome may be suggested because of all of these correlations, but little experimental evidence have been ready to evaluate this theory. An exceptionally higher BMI was found in fragile older adults in a detailed analysis of certain physicochemical measures correlated with the frailty phenotype than in someone who is not frail or were pre-frail [16].

The long-term physiological effects of infection with SARSCoV-2 (Severe Acute Respiratory Syndrome Coronavirus) are not understood. It is possible to ignore the potential of COVID-19 to induce chronic disease, sarcopenia, and physical functional decline and go beyond the expected respiratory consequences [17]. In fact, in COVID-19 patients, the cytokine system is considered to have a short life expectancy due to a higher inflammatory response [18]. In general, we clearly emphasize that prevention efforts for frailty/sarcopenia will improve the attack to COVID-19 as well as exercise, diet and vitamin (D) supplements [18]. In addition, incorporating nutritional strategies, lifestyle improvements and therapies that can improve muscle architecture and function is important. Recovery measures should be launched as fast as possible, considering that elderly individuals have a lower capacity to recover muscle loss after disuse. It is interesting to note that resistance exercises have indeed been widely acknowledged for enhancing muscle mass, strength, and function in older people. Resistance training should therefore be an essential aspect of the requisite public health education programs to minimise the impact of the COVID-19 quarantine on the security of the muscle tissue. We may theoretically direct governments to prevent a behavioral disorder and recovery crisis post-COVID-19 by providing a variety of home-based interventions, particularly resistance exercise, 
greater protein intakes and supplementation. These techniques can also serve as effective preventive measures to minimize the risk of sarcopenia overall and in the event of potential isolation periods.

\section{Disclosure Statement}

The authors declare that there are no conflicts of interest.

\section{References}

1. Giri S, Williams G, Rosko A, SJ Grant, HS Mian, et al. (2020) Simplified frailty assessment tools: are we really capturing frailty or something else?. Leukemia 34(7): 1967-1969.

2. Motta F, Sica A, Selmi C (2020) Frailty in Rheumatic Diseases. Front Immunol 11: 576134.

3. Santos Morais Junior G, Ignacio Valenzuela Perez D, Cecília TonetFurioso A, Lucy G, Karla Helena CV, et al. (2020) Circulating Interleukin-6 (but Not Other Immune Mediators) Associates with Criteria for Fried's Frailty among Very Old Adults. J Aging Res 2020: 6831791.

4. Nwadiugwu MC (2020) Frailty and the Risk of Polypharmacy in the Older Person: Enabling and Preventative Approaches. J Aging Res 2020(3): 6759521

5. Kim DH (2020) Measuring Frailty in Health Care Databases for Clinical Care and Research. Ann Geriatr Med Res 24(2): 62-74.

6. Xue QL, Bandeen-Roche K, Tian J, Kasper JD, Fried LP (2020) Progression of Physical Frailty and the Risk of All-Cause Mortality: Is There a Point of No Return? J Am Geriatr Soc.

7. Eisenberg Y, Vanderbom KA, Harris K, Herman C, Hefelfinger J, et al (2021) Evaluation of the Reaching People with Disabilities through Healthy Communities Project. Disabil Health J 101061.

8. Zhang X, Wang C, Dou Q Zhang W, Yang Y, et al. (2018) Sarcopenia as a predictor of all-cause mortality among older nursing home residents: a systematic review and meta-analysis. BMJ Open 8(11): e021252.

\section{ISSN: 2574-1241}

DOI: 10.26717/BJSTR.2021.33.005470

Carmine Finelli. Biomed J Sci \& Tech Res

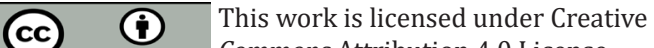
Commons Attribution 4.0 License

Submission Link: https://biomedres.us/submit-manuscript.php
9. Morishita Y, Sakuma K, Chao CT (2021) Frailty and Sarcopenia in Various Cachectic Kidney Diseases. Front Med (Lausanne) 7: 627485.

10. Veronese N, Smith L, Barbagallo M, Lin Y, L Zou, et al. (2021) Sarcopenia and fall-related injury among older adults in five low- and middleincome countries. Exp Gerontol 147: 111262.

11. Alhussain MH, Alkahtani S, Aljuhani O, Habib SS (2020) Effects of Nutrient Intake on Diagnostic Measures of Sarcopenia among Arab Men: A Cross-Sectional Study. Nutrients 13(1): 114.

12. Billot M, Calvani R, Urtamo A, Juan Luis Sánchez Sánchez, Cecilia Ciccolari-Micaldi, et al. (2020) Preserving Mobility in Older Adults with Physical Frailty and Sarcopenia: Opportunities, Challenges and Recommendations for Physical Activity Interventions. Clin Interv Aging 2020(1675): 1690 .

13. Silveira EA, Souza JD, Santos ASEAC, Canheta ABS, Pagotto V, et al. (2020) What are the factors associated with sarcopenia-related variables in adult women with severe obesity?. Arch Public Health 78(1): 71.

14. Tarantino G, Finelli C, Colao A, Domenico Capone, Marianna Tarantino, et al. (2012) Are hepatic steatosis and carotid intima media thickness associated in obese patients with normal or slightly elevated gammaglutamyl-transferase?. J Transl Med 10: 50.

15. Sahni S, Dufour AB, Fielding RA (2020) Total carotenoid intake is associated with reduced loss of grip strength and gait speed over time in adults: The Framingham Offspring Study. Am J Clin Nutr 113(1).

16. Kiuchi Y, Makizako H, Nakai Y, K Tomioka, Mika K, et al. (2021) The Association between Dietary Variety and Physical Frailty in CommunityDwelling Older Adults. Healthcare (Basel) 9(1): 32.

17. Casey P, Ang Y, Sultan J (2021) COVID-19-induced sarcopenia and physical deconditioning may require reassessment of surgical risk for patients with cancer. World J Surg Oncol 19(1): 8.

18. Ekiz T, Kara M, Özçakar L (2020) Fighting against frailty and sarcopenia - As well as COVID-19?. Med Hypotheses 144: 109911.

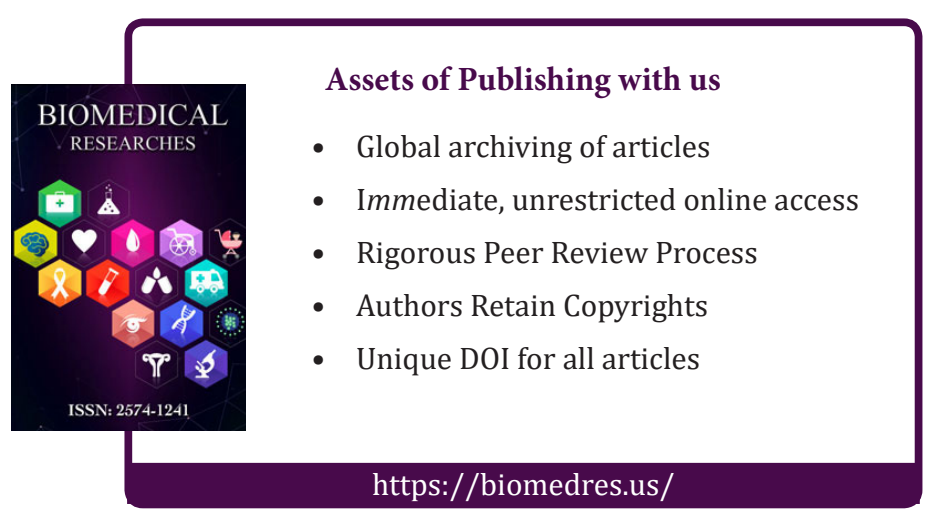

